\title{
ENTRE COBRAS E PLANTAS, MUITAS GLÂNDULAS: A PRODUÇÃO DE HORMÔNIOS E ASSISTÊNCIA ÀS DOENÇAS ENDOCRINOLÓGICAS NO INSTITUTO BUTANTAN - 1917-1945
}

\author{
Between Snakes and Plants, Several Glands: The Hormones Production and the \\ Assistance to the Endocrinological Diseases in Butantan Institute - 1917-19451
}

Rodrigo Ramos Lima*

\begin{abstract}
Resumo: O presente artigo versa sobre a elaboração de produtos hormonais e assistência aos portadores de disfunções glandulares, no Instituto Butantan, na primeira metade do século XX. Desse modo, indico três marcos na elaboração de saberes, técnicas e produtos hormonais na instituição biomédica paulista, quais sejam: a produção de opoterápicos (1917-1925), a construção científica de conhecimentos em endocrinologia, na Seção de Fisiopatologia Experimental (19341940) e a instituição do Serviço de Endocrinologia Humana (1940-1945), dedicado em atender pacientes com endocrinopatias. Neste artigo, foram analisados os relatórios administrativos, bulas médicas, periódicos científicos, acervo fotográfico e depoimentos de cientistas que atuaram na instituição. Assim, apresento a atuação do Instituto Butantan no tratamento das disfunções hormonais no contexto de emergência das doenças glandulares como problema de saúde pública no Brasil, na primeira metade do século XX.

Palavras Chave: Hormônios, Instituto Butantan, Doenças Endocrinológicas.
\end{abstract}

Abstract: This article deals with the development of hormonal products and assistance to glandular dysfunction patients at the Butantan Institute in the first half of the 20th century. Thus, I indicate three milestones in the production of knowledges, techniques and in the elaboration of hormonal products in this biomedical institution, namely: the production of the glands extracts (1917-1925), the scientific production of knowledge in Endocrinology, in the Experimental Pathophysiology Section (1934-1940), and the institution of the Human Endocrinology Service (1940-1945), dedicated to treating patients with endocrinopathies. The main sources analyzed were administrative reports, medical leaflets, photographic collection, scientific journals and testimonial of scientists who worked at the institution. As a result, I present the role played by Butantan Institute in the treatment of hormonal disorders in the context of the emergence of glandular diseases as a public health problem in Brazil in the first half of the twentieth century.

Keywords: Hormones, Butantan Institute, Endocrinological Diseases.

Em junho de 1889, o cientista Charles Edouard Brown Sécquard (1817-1894), conhecido por seus estudos na área de neurofisiologia e por ter sucedido Claude Bernard (1813-1878) na cadeira de fisiologia, compareceu à Academia Nacional de Medicina de Paris para anunciar suas experiências com injeções de extratos testiculares de cachorros e porcos da guiné que aplicava em

10 presente trabalho foi realizado com apoio da Coordenação de Aperfeiçoamento de Pessoal de Nível Superior - Brasil (CAPES) - Código de Financiamento 001.

* Doutorando no Programa de Pós-graduação em História das Ciências e da Saúde - Casa de Oswaldo Cruz

- FIOCRUZ. ORCID: http://orcid.org/0000-0001-7652-735X E-mail: contatomagisterio@hotmail.com 
si mesmo. Desde então, alegou que sentia maior disposição para as tarefas diárias e sensação de bem-estar ampliada. Em tese, suas pesquisas visavam provar ser possível restaurar a jovialidade e a capacidade criativa dos homens. Anos depois, seu uso ficou atrelado à promoção da virilidade e ao revigoramento da sexualidade masculina. Para as mulheres, os preparados químicos oriundos de ovários destes mesmos animais eram receitados com fins de tratar vítimas de histeria, problemas de útero e debilidade devido à idade. Sequard criou condições para que muitos fisiologistas e endocrinologistas elaborassem discussões acirradas a respeito da veracidade de seus métodos, bem como promoveu incertezas ante ao fato de que somente as glândulas sexuais eram responsáveis pelo desenvolvimento sadio da sexualidade humana. Desde então, os trabalhos de Brown Sécquard constituíram-se como marco do nascimento da opoterapia - oriunda do grego opós: sucos-extratos; therapia: tratamento- profilaxia, e também chamada de organoterapia -, isto é, o tratamento das disfunções das glândulas de secreção interna com o extrato organoterápico da respectiva glândula em estágio de hipofunção (BORELL, 1976).

A utilização dos órgãos de secreção interna não ficou restringida aos testículos e abarcou um variado conjunto de afecções ligadas a diversas glândulas Em seguida, em 1891, o cientista George Redmayne Murray (1865-1939) reportou nos principais periódicos médicos londrinos a cura do mixedema a partir de injeções subcutâneas do extrato da tireoide. Três anos depois, George Oliver (1883-1965) e Edward Schafer (1850-1935) trouxeram suas observações sobre os efeitos vasopressores dos extratos de adrenalina. Em 1896, William Osler (1849-1919) noticiou a utilização dos sumos de adrenalina no tratamento do mal de Addison. Desde então, as experiências fisiológicas com as glândulas de secreção interna visaram estabelecer os principais padrões laboratoriais que permitiriam compreender os mecanismos dos compostos glandulares. Em 1905, foi a vez do cientista britânico Ernest Starling (1866-1927) formular o termo hormônio, designando-o como coordenador químico, isto é, o responsável por influenciar outros órgãos do corpo (BORELL, 1976; OUDSHOORN, 1994). Em 1921, o isolamento da insulina com base em compostos pancreáticos, realizado por Frederick Banting (1891-1941) e Charles Best (1899-1978), revolucionou o tratamento das diabetes e revigorou as promessas dos extratos glandulares (TATTERSALL, 1998). Posteriormente, o poder terapêutico dos órgãos de secreção interna foi reforçado na década seguinte com a concessão do Prêmio Nobel em 1934, para George Whipple (1878-1976) e equipe, em função de sua recomendação dos extratos de fígado no tratamento das anemias perniciosas (PITELLA, 2018; BECALOSSI, 2018). Nas páginas a seguir, trato desta classe de medicamentos elaborados com base em órgãos de animais que poderiam estimular correlações orgânicas de cura, de reequilíbrio e suplementação de glândulas que quedavam em disfunção, ou haviam sido extirpadas (LIMA, 2016).

\section{Prêambulo}

No relatório apresentado pela Diretoria do Serviço Sanitário, assinado pelo sanitarista Arthur Neiva (1880-1943) e entregue ao Secretário do Interior de São Paulo em 1916, foi recomendado que o Instituto Butantan deveria desenvolver a seção de produtos opoterápicos, tal qual era produzido pelo Instituto Bacteriológico de Buenos Aires. Cumpre notar que, antes de assumir a gestão do instituto paulista ${ }^{2}$, Neiva geriu o instituto bacteriológico argentino, que era reconhecido naquela altura como um dos maiores centros de estudos sobre hormônios na América Latina

2 Arthur Neiva foi diretor do Instituto Butantan entre 07/12/1919 e 20/03/1921. 
(CUETO, 1994; MANZONI, 2013). Assim, no ofício encaminhado por Neiva, foi enfatizado que as preparações glandulares tinham "grande saída, pois o capítulo da patologia atinente às afecções ligadas ao mau funcionamento das glândulas de secreção interna cada vez ganha mais importância" (Relatório da Diretoria do Serviço Sanitário ao secretário do Interior, 25 dez.1916. Arquivo Arthur Neiva. Extraído de BENCHIMOL; TEIXEIRA, 1993:p.127).

Desde a entrada de Arthur Neiva na direção do Serviço Sanitário de São Paulo, em dezembro de 1916, o Instituto Butantan (IB) recebeu considerável investimento em suas dependências, e sua posição estratégica no fornecimento de bioterápicos foi vista como importante competidora frente ao legado de Oswaldo Cruz, no plano das ciências biomédicas no Brasil. Nesse sentido, Arthur Neiva empreendeu reformas no serviço sanitário paulista que concederam ao IB a expansão de suas atividades, expressas na inserção de estudos em veterinária, doenças vegetais, aprimoramento das pesquisas sobre doenças parasitárias, entomologia, cultivo de plantas medicinais e na fabricação de produtos químicos e opoterápicos, o que levou ao aumento do quadro de funcionários e da sua arrecadação orçamentária (BENCHIMOL; TEIXEIRA, 1993).

De acordo com Benchimol e Teixeira (1993), Arthur Neiva ambicionou gerir o Instituto de modo que "sobrepujasse o Instituto Oswaldo Cruz, tanto no que concerne à latitude de suas funções quanto à latitude geopolítica de sua influência" (BENCHIMOL; TEIXEIRA, 1993, p: 161). Destacou-se nesse cenário de reformas a criação da seção de Química, do Horto Oswaldo Cruz e do Serviço de Medicamentos Oficiais. Desse modo, através do programa de educação para a saúde, o Butantan aproximou seus contatos com "as ações articuladas no estado contra as endemias rurais" (Idem).

Benchimol e Teixeira (1993) também indicaram que o ambiente era propício para as metas elaboradas por Arthur Neiva. Devido à Primeira Guerra Mundial, os países envolvidos produziam para os exércitos beligerantes e o fornecimento de medicamentos estrangeiros assistiu drástica redução. Ademais, o Instituto Oswaldo Cruz não dava conta de suprir a demanda nacional de bioterápicos e, sobretudo, não atuava na elaboração de soros antiofídicos e afins. Nesse contexto, a ampliação das atribuições do IB como pujante fornecedor de bioterápicos ganhou maior aderência, mormente quando cotejadas as possibilidades de vendas, tanto para o mercado brasileiro quanto para os países da América do Sul (BENCHIMOL; TEIXEIRA, 1993,p. 113).

Na obra Cobras, lagartos e outros bichos, de Benchimol e Teixeira (1993), os autores assinalaram que a seção de química do Instituto Butantan produziu medicamentos para o tratamento da malária, ancilostomíase, disenteria, lepra, dentre outras. Após Arthur Neiva promover reformas para a saúde pública paulista, o IB sofreu um impulso para a produção de bioterápicos. Em 1917, eram dez os itens fornecidos para o mercado; dois anos depois, esse número ultrapassou cem itens, entre os quais destacaram-se quimioterápicos e opoterápicos que eram comercializados e consumidos, "com ou sem a intermediação dos clínicos - por uma população que extravasava o universo alvo da saúde pública" (Idem). Desse modo, os autores apontaram que a opoterapia fez parte do conjunto de medicamentos produzidos pelo instituto ofídico e indicaram o turbulento caso das fiscalizações de seroterápicos e opoterápicos registrado no relatório de Ulhôa Cintra, em 1918. Como esta classe de medicamentos não foi objeto de estudo nesta obra, acompanho neste artigo a elaboração e produção de opoterápicos no Instituto Butantan no pós-1920.

A rigor, a tradição memorialística da história da medicina registrou passos importantes da produção de saberes e conhecimentos nos ramos da fisiologia e da farmacologia brasileira. Desde as reflexões sobre a originalidade das pesquisas neste ramo nos tempos coloniais até o desenrolar da fisiologia no Museu Nacional durante o século XIX, as narrativas em torno deste campo das 
ciências da vida destacaram-se pelo registro dos atores, instituições e principais repercussões dos estudos brasileiros em fisiologia no cenário internacional (GOMES, 2013; SOUZA, 2015; VALLE, 1979). Com esse horizonte, utilizo os relatórios administrativos anuais da instituição, com o argumento de que a trajetória do Instituto Butantan na produção de organoterapias ${ }^{3}$ pode ser interpretada como importante lócus de investigação sobre o processo de especialização da endocrinologia no Brasil; eles são analisados a partir da produção de terapêuticas hormonais, das pesquisas experimentais na área da fisiopatologia experimental e da instituição da assistência aos portadores de endocrinopatias. Por esse caminho, evito utilizar termos como pseudociência ou ciência superada, com fins de demonstrar a prática da recepção dos saberes hormonais pelo IB, com o objetivo de compreendermos os impactos de sua circulação no contexto local paulista. Com essa perspectiva, pretendo ampliar o escopo das recentes e importantes contribuições historiográficas que tomaram a história da endocrinologia em face de suas íntimas relações com os saberes criminológicos (OLIVEIRA JÚNIOR, 2006; FERLA, 2009), ressaltando que o chamariz de sua sustentação e adesão em diversos campos biomédicos residia, em grande medida, no seu contingente terapêutico.

\section{Órgãos que curam: a produção de conhecimentos em hormônios no Instituto Butantan, 1917-1925}

Em janeiro de 1917, o relatório administrativo do Instituto Butantan relatava que o médico Octavio Veiga trouxe uma breve discussão acerca dos efeitos do soro normal de cavalo e soro crotálico no tratamento da epilepsia. As experiências realizadas no Hospício Nacional de Alienados, em parceria com o psiquiatra Francisco Franco da Rocha (1864-1933), vinham sinalizando para a necessidade de produzir mais pesquisas, tendo em vista o curto período de observação e o reduzido número de doentes. Os médicos chegaram à "impressão de que nem o soro, nem a peçonha tivessem uma grande influência sobre a marcha da epilepsia". Coube ao médico Felippe Aché continuar o uso do soro normal no tratamento da epilepsia, mesmo reconhecendo que era "insuficiente na maioria dos casos" ( RELATÓRIO ANUAL DO INSTITUTO BUTANTAN, 1917, p.5). Desse modo, Octavio Veiga alegou que seria necessário decompor o soro em "grupos de substâncias" com fins de averiguar qual destes seria exequível no tratamento da doença. Com a proposta de precipitar os proteídeos do soro, chegariam à sua concentração, o que levaria aos "lipoides circulantes, produtos de secreção interna, etc.” (Idem).

Desde então, estas substâncias foram intituladas como "soro hormônico" ou "soro tônicoestimulante", acionadas por Aché "em todos os casos em que empregava então o soro normal de cavalo". A diferença do soro hormônico seria sua concentração, pois apresentava uma redução de "cinco vezes o volume primitivo". Outro argumento favorável para sua utilização residia na "vantagem da concentração", pois não provocava "os fenômenos anafiláticos nem outras perturbações tão frequentes com o uso do soro normal”. Por isso, foi empregado como ensaio no Hospício de Juquery e em doentes de clínicas particulares, onde atuava "principalmente como tônico estimulante do sistema nervoso e das glândulas internas". Assim, o estudo do produto continuaria, "na esperança de que ele venha prestar inestimáveis serviços no tratamento de várias perturbações do sistema nervoso" (RELATÓRIO ANUAL DO INSTITUTO BUTANTAN, 1917,p. 5-6).

O relato acima aponta para a inserção dos lipoides no tratamento de doenças psiquiátricas no âmbito asilar e pode ser considerado como ponto de partida do interesse dos cientistas alocados

3 Neste trabalho utilizo os termos opoterapia e organoterapia como sinônimos. 
no IB pelas doenças do sistema nervoso e das glândulas de secreção interna. Obtidos por métodos diferentes dos opoterápicos, sua aproximação com estes era notável, pois em sua composição havia sangues, tecidos e substâncias extraídas de animais. Consoante a essa interpretação, situam-se as contribuições do pesquisador Luiz Antônio Teixeira (1995) que também encontrou produção semelhante no Instituto Pasteur paulista e incluiu estes soros no campo da produção opoterápica. De acordo com o autor, o soro renal de cabra era indicado no tratamento das nefrites ou inflamações nos rins, e o soro normal de cavalo era fornecido no tratamento de hemorragias, anemias e moléstias discráticas ( TEIXEIRA, 1995, p.86). Assim, a análise contínua dos relatórios do Instituto Butantan permite enunciar que esta classe de medicamentos se constituiu como ponto de partida para a produção de opoterapias e tornou-se um significativo ramo de medicamentos entregue ao mercado de bioterápicos para os serviços de saúde pública paulista e de outras capitais do país, entre 1917-1925.

No primeiro trimestre de 1917, foram vendidas 375 caixas de soro renal caprino, rendendo um total de 5:625\$000 para a renda total. No findar do ano, o estoque contava com 70 ampolas de soro renal caprino (1:050\$000) e o soro antitóxico gravídico com 30 caixas (300\$000) e o soro neurotônico com 40 caixas $(300 \$ 000)$. A venda bruta de soros antitóxico gravídicos foi de 12 ampolas, alcançando um total de 120\$000. Para o Hospital de Isolamento, foram enviados 12 tubos $(180 \$ 000)$ e 5 tubos enviados como amostras $(75 \$ 000)$. Já o soro antitóxico gravídico contou com envio de 6 tubos de amostras, no quarto trimestre de 1917 (60\$000), o renal caprino com 6 doações (90\$000) e o soro hemostático com 2 envios (20\$000) (RELATÓRIO ANUAL DO INSTITUTO BUTANTAN, 1917,p.51).

Convém notar a produção do Lipo-Soro Neurotrófico A36 ou Neurotan, indicado para reconstituição geral do organismo, composto por lipoides receituários, sanguíneos e excipientes. Igualmente, foram vendidos o Lipo-Soro Neurotrófico B, indicado para os "estados de esgotamento nervoso, desequilíbrio das funções psíquicas e adinamia geral". Outro produto desta linha acionado nas clínicas ginecológicas e procedimentos obstétricos, composto de extratos de sangue de éguas grávidas, foi o Lipo-Soro Anti-ToxiGravídico (Nos. 102-103), também chamado de Gravitan B. Indicado para os tratamentos da albuminúria, vômitos incoercíveis da gravidez e acessos de eclampsia (PRODUTOS DE Nº 100-101. BULAS-1B-CX 0542. 1918. Acervo Instituto Butantan. Núcleo de Documentação. São Paulo. Brasil).

As fontes analisadas forneceram dados sobre a participação dos Matadouros Municipais e Continentais da cidade paulista, que ensinavam os funcionários do Instituto Butantan:

[...] a melhor e mais segura técnica para a colheita perfeita dos órgãos e glândulas necessárias à confecção dos produtos opoterápicos. Tentei e obtive o fornecimento gracioso desses órgãos, exceto das hipófises cuja retirada dá bastante trabalho, dos cérebros, baços e fígados que tem grande procura para o consumo público, dando assim ensejo a que fizéssemos notável economia, conforme se pode calcular, atendendo-se a grandes quantidades de glândulas que então recebemos [...] (RELATÓRIO ANUAL DO INSTITUTO BUTANTAN, 1918, p.136).

Nas páginas do relatório de janeiro de 1919 emergiu pela primeira vez a criação da seção de "Opotherapia, sangrias, trabalho hospitalar, fiscalização de produtos". Naquela altura, a direção do Instituto Butantan estava sob a liderança do herpetólogo Afrânio de Amaral (1894-1982), um dos principais defensores das pesquisas opoterápicas e em endocrinologia. No findar do ano, além dos soros, tuberculinas, óleos e soluções medicamentosas, foram entregues ao mercado $2.011 \mathrm{am}$ polas de soro-tóxico-gravídico, 4.016 de soro hemostático, 24.102 ampolas de extratos orgânicos 
injetáveis. Do conjunto de substâncias que deveriam ser consumidas por via gástrica, foram 1.118 frascos e 50 frascos de comprimidos de órgãos (RELATÓRIO ANUAL DO INSTITUTO BUTANTAN, 1919,p.9).

É importante notar a referência aos fornecedores de órgãos de animais para o instituto, bem como da especialização necessária para que fossem extraídos os insumos para a produção de opoterápicos. Nesse mesmo ano, em função da trágica epidemia de gripe espanhola que assolou a capital paulista, os trabalhos foram intensos, de modo que "não houvesse falta de nenhum produto opoterápico", afirmou Amaral, que resolveu inserir o soro normal no tratamento da doença. Motivado pelo êxito das experiências, organizou junto com o professor Oscar Freire, da Faculdade de Medicina de São Paulo e da Bahia - que, naquela ocasião, atuava no Serviço Sanitário -, o Serviço Clínico no Hospital da Escola de Farmácia, onde as aplicações soroterápicas continuaram (RELATÓRIO ANUAL DO INSTITUTO BUTANTAN, 1919,p.144). Durante a gestão de Amaral, os investimentos em estudos endocrinológicos estiveram relacionados com suas atividades clínicas, constituindo-se como elementos que incentivaram a elaboração de novos preparados glandulares. Por essas razões, Amaral enfatizou a importância de produzir extratos contra a asma, pois havia obtido bons resultados com o "extrato pluriglandular", em seis pacientes, e, em especial, numa irmã de caridade acometida por forte crise "bronco-pulmonar da gripe".

Importante lembrarmos que o Instituto Butantan instituiu sistemas de permutas de cobras peçonhentas por substâncias bioterápicas (BENCHIMOL; TEIXEIRA, 1993, p.82). Além de seringas e soros diversos, o instituto também forneceu opoterápicos nesse sistema de escambo. No terceiro trimestre de 1918, por exemplo, foram enviados 6 ampolas de extrato orcheino $(5 \$ 000)$. No semestre seguinte, foram entregues 1 ampola de extrato tireo-privo (5\$000) e 12 ampolas de produtos opoterápicos não especificados (10\$000) (RELATÓRIO ANUAL DO INSTITUTO BUTANTAN, 1918, p.65).

No ano seguinte, as produções bioterápicas do Instituto Butantan foram alvo de um atento movimento de fiscalização e os resultados foram desapontadores. Para Ulhôa Cintra, então diretor interino, a seção de opoterapia não estava instalada adequadamente, de modo a elaborar cientificamente os medicamentos. Constatou-se também que somente os exames culturais de soros, vacinas e opoterápicos foram executados pela gestão anterior, e que, entre 9 de setembro de 1918 e 30 de junho de 1919, somente a sacarose havia sido submetida a testes de verificação de esterilidade. A queixa residia no fato de que os produtos estavam sendo aquecidos somente uma vez a 60 graus C, quando o correto seriam dois aquecimentos, o primeiro como já era aplicado e o segundo a 100 graus C no momento do seu acondicionamento. Desse modo, os registros indicaram a falta de qualidade de alguns produtos opoterápicos pelo critério da época, fazendo com que Cintra suspendesse os serviços da seção, pois não podia "com consciência e critério científico, ajuizar dos diversos produtos preparados pelo Instituto, nem dos congêneres existentes na praça, pela falta de pontos de referência" (RELATÓRIO ANUAL DO INSTITUTO BUTANTAN, 1919, p.183). Convém notar que esses dados podem ser vistos como evidências das consequências do pouco investimento em aparelhagens para a seção, solicitadas desde o momento de sua fundação, no ano anterior.

No entanto, estes entraves não devem ser vistos como marcos decisivos para a interrupção da produção dos opoterápicos. A seção de opoterápicos foi a única que não apresentou

\footnotetext{
${ }_{4}^{4}$ Dois anos depois, o compromisso com as pesquisas com este extrato foi reafirmado, "pois já possuo para mais de 30 observações, tendo verificado que diversos pacientes se reputam inteiramente curados" (RELATÓRIO ANUAL DO INSTITUTO BUTANTAN, 1920, p.18)
} 
irregularidades no aquecimento dos produtos, pois vinha praticando o procedimento padrão, isto é, aquecia as substâncias em dois momentos, o primeiro a $60^{\circ}$ Celsius e o segundo a $100^{\circ}$, o que demonstra uma diferenciada preocupação de Amaral com estes produtos e um maior controle de sua qualidade. No entanto, ficou constatado que os soros antitóxico gravídico e neuro-tônico estavam estéreis e o eumênico contaminado. Dos opoterápicos que apresentaram esterilidade, constavam os extratos ganglionar, hipófise anterior, justarenino e tímico. O extrato de hipófise total estava contaminado e o extrato ovárico apresentou turvações (RELATÓRIO ANUAL DO INSTITUTO BUTANTAN, 1919, p.178-182).

Cintra finalizou o relatório da seção informando que sua breve gestão no Butantan não conseguiu levar melhorias a este ramo de fármacos (IDEM,p.183). Benchimol e Teixeira também comentaram esse episódio e deram especial atenção ao relatório de Ulhôa Cintra, inserindo-o no contexto mais amplo de crises vividas pelo Instituto Butantan com a saída do ex-diretor Vital Brazil, aposentado em junho de 1919. Para os autores, este caso provocou uma fratura no projeto concebido por Neiva para o instituto: o Butantan não se mostrava capaz de superar Manguinhos na fabricação de produtos biológicos. Entretanto, os documentos pesquisados apontam para a contínua inserção de pequenas reformas na seção de opoterapias, bem como a constante reinvindicação de melhorias desta, num indício que sugere a legitimidade institucional de que gozava a produção de opoterápicos naquele momento.

Com a saída de Ulhôa Cintra, a direção do Butantan foi entregue a Arthur Neiva em dezembro de 1919, cargo que ocupou até março de 1921. Desde então, o episódio das fiscalizações dos produtos do instituto serviu como elemento importante na implementação das mudanças necessárias e os procedimentos de rotina na produção de bioterápicos foram reelaborados. No relatório apresentado pelo diretor da seção de opoterapias, Afrânio do Amaral assinalou que as atividades da seção não foram interrompidas e o aperfeiçoamento da técnica para a elaboração de comprimidos com substâncias glandulares foi conseguido, "os quais agora podem ser confrontados com vantagem com os melhores que veem no mercado", principalmente pelo seu "peso, consistência e aspecto", e, especialmente, pela “dosagem que é a mais regular que tenho encontrado". A produção tinha como facilitador uma reserva de órgãos dessecados provenientes do ano anterior, e que, somadas aos órgãos recebidos naquele ano, "pude aumentar a produção dos diversos preparados, que felizmente tem tido boa aceitação" (RELATÓRIO ANUAL DO INSTITUTO BUTANTAN, 1919, p.186). O provimento de órgãos contou com a colaboração do Matadouro Municipal e destaque especial foi dado aos "Continental Products $C \Omega$ M. Dos carneiros foram extraídas 364 tireoides e dos bois 384. Os ovários de vacas e porcas concedidos foram 872/68, respectivamente. Dos vitelos foram retirados 28 metatorsos. Além destes, foram entregues à seção 14 baços, 22 cérebros, 12 pâncreas, 58 testículos, 32 timos, 198 suprarrenais e 5.567 hipófises (Idem). 
Figura 1: Edifícios onde se localiza: Serpentário das não venenosas, Opotherapia - sala de machinas - biotherio e cocheira-enfermaria (autoria desconhecida) (1920)/ Buildings where it is located: Serpentarium of non-venous, Opotherapia - room of machines - biotherium and stable-ward. (unknown author)

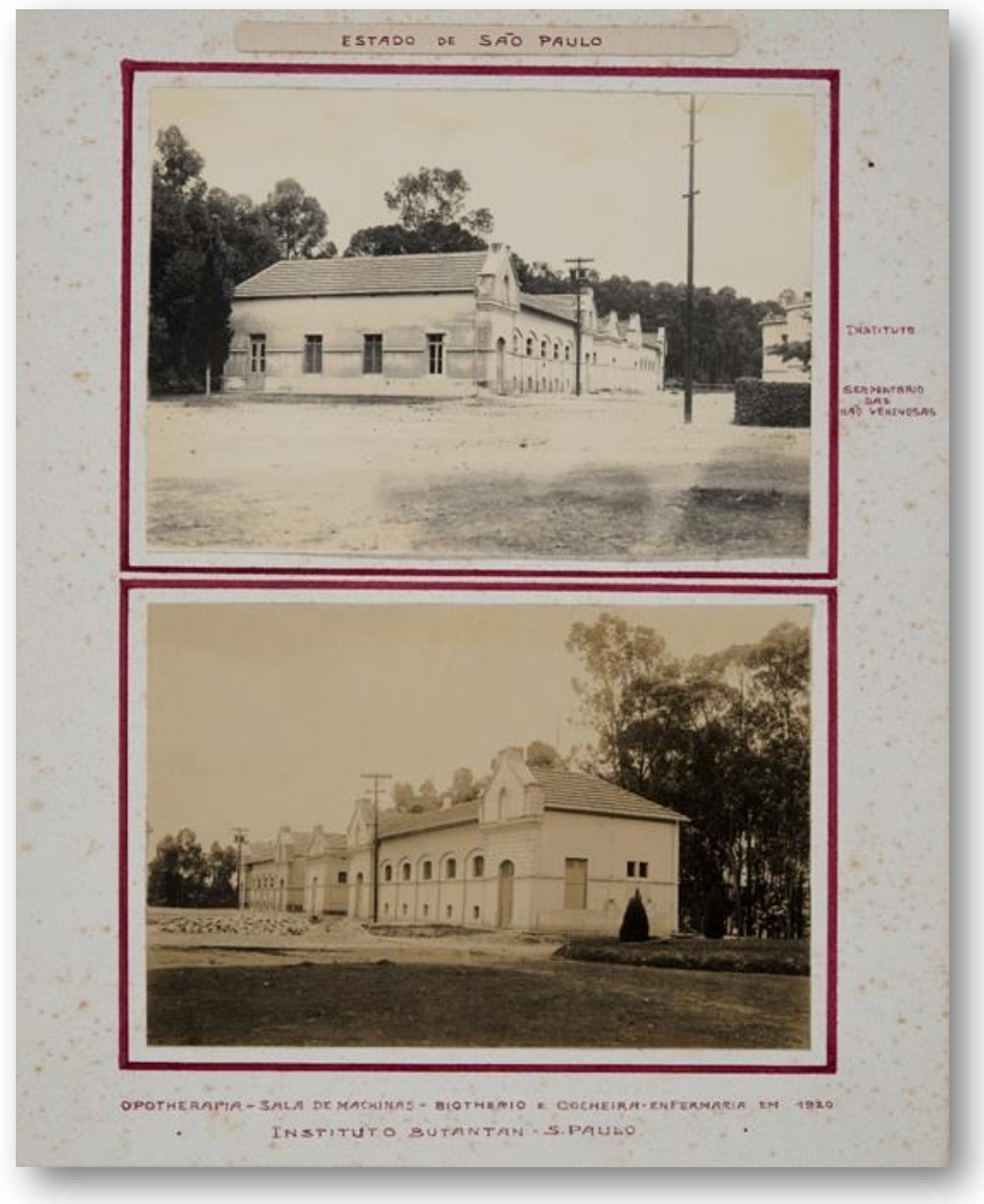

Fonte: IB_ICO_010254. Acervo Instituto Butantan/ Centro de Memória. São Paulo, Brasil.

As reinvindicações administrativas seguintes dão conta das solicitações de aperfeiçoamento da seção de opoterapia, o que proporcionaria o aumento da "pesquisa básica" e da inserção do Instituto Butantã como importante núcleo de produção de conhecimentos em endocrinologia e fisiologia (RELATÓRIO ANUAL DO INSTITUTO BUTANTAN, 1918, p.187). Nesse primeiro período, a manutenção da seção de opoterapia foi priorizada pelo aspecto comercial dos extratos 
glandulares, mais do que pelo estímulo à produção de trabalhos científicos em diálogo com a comunidade científica nacional ou internacional. Pelo que podemos ver, as condições de baixo investimento na seção podem ser consideradas elementos cruciais para que a produção organoterápica no Instituto perdesse seu papel de concorrente frente aos institutos privados (RELATÓRIO ANUAL DO INSTITUTO BUTANTAN, 1921, p.83). Mais adiante, o ano de 1921 trouxe importantes mudanças na infraestrutura da seção, visto que o instituto paulista passou a contar com a direção do cientista tcheco Rudoulf Kraus, renomado cientista que havia atuado como gestor do Instituto Bacteriológico de Buenos Aires, principal região sul americana expoente em estudos com hormônios, em escala transnacional (CUETO, 1994).

Destarte, as fontes disponíveis trazem dados efusivos sobre a constante produção de extratos hormonais entre 1918 e 1925, ano de sua brusca interrupção pelas mãos de Vital Brazil (18651950), quando do seu retorno na direção do $I^{5}{ }^{5}$. Nestes registros, encontram-se valiosas informações sobre a quantidade de órgãos utilizados para a produção de opoterápicos, lista de movimentação dos produtos vendidos por trimestre e seus respectivos valores. Nesse período, foram fornecidos os seguintes extratos em comprimidos: ovárico, esplênico, hepático, hipófise posterior, hiperplástico, suprarrenal, tímico, tireóideo e testicular. Em forma pura saíram para as prateleiras os extratos orcheíno, mamário, cerebral, suprarrenal, hepático, tireóideo, hematogênico, hepático, hipófise posterior e total, testicular, ovárico e tímico (RELATÓRIOS ANUAIS DO INSTITUTO BUTANTAN, 1918 a 1924).

\section{Entre órgãos e publicações: o desenvolvimento de novas linhas de pesquisas com hormônios nos anos 1930}

Durante o governo de Getúlio Vargas (1882-1954), na década de 1930, o Estado de São Paulo buscou investir em pesquisas científicas e tecnológicas, num processo que incluía a formação de uma intelectualidade sintonizada com estes objetivos. Em março de 1931, o instituto paulista foi desmembrado do conjunto das organizações de saúde pública e foi inserido no organograma da recém-criada Secretaria de Educação e de Saúde Pública. De acordo com Teixeira (2016), o IB alcançou, nesses anos, o status de centro de medicina experimental, indo além da produção de bioterápicos ao investir em estudos sobre a medicina humana e animais venenosos. Por outro lado, novas contratações de renomados pesquisadores estrangeiros foram facilitadas, posto que, em função do crescente antissemitismo na Europa, cientistas foram atraídos pela possibilidade de imigrar para o Brasil. Um dos primeiros pesquisadores deste grupo foi o químico alemão Karl Henrique Slotta (1895-1987), que chegou no IB em 1935 para gerir a Seção de Química e Farmacologia

\footnotetext{
${ }^{5}$ Vital Brazil conhecia a força econômica que os produtos opoterápicos forneciam. Por isso, a opoterapia ocupou lugar de destaque no conjunto de produtos biológicos fornecidos pelo Instituto Vital Brazil, em Niterói. No Catálogo com indicações sobre a aplicação de alguns dos produtos do Instituto, publicado em 1920, é possível acompanhar a multiplicidade de produtos opoterápicos elaborados pelo Instituto Vital Brazil, bem como observar como os compostos com novas substâncias foram divididos por especialidades. Não obstante, através do catálogo de vendas dos produtos de seu instituto, podemos perceber que a oferta de opoterápicos (31) superava a de vacinas (11), solutos medicamentosos (30) e tuberculinas, maleínas e outros produtos (10) .Outra evidência que aponta para a permanência da produção opoterápica no conjunto dos trabalhos realizados pelo Instituto Vital Brazil diz respeito à Divisão de Medicina Veterinária, Notícia sobre o seu funcionamento, suas atividades, sua produção, com indicador terapêutico, lançado em 1941, onde podemos encontrar farto material de indicações de opoterapias para tratar inúmeras afecções em cães, ovelhas, touros, vacas, cavalos e cabras. INSTITUTO VITAL BRAZIL. Catálogo com indicações sobre a aplicação de alguns dos produtos do Instituto. São Paulo. 1920.
} 
Experimental. Slotta passou três anos em atividade e obteve apoio de seus assistentes Klaus Neisser (1937-1938), Gherard Szyszka (1935-1938) e dos pesquisadores Dioniso von von Ubish (19351937), Sara Kaufmann (1931-1935) e Paulo König (1935-1938), conseguindo, assim, isolar a crotoxina, proteína tóxica do veneno de cascavel. Slotta também foi reconhecido internacionalmente pelas pesquisas que conduziram ao isolamento da progesterona, hormônio feminino (IBANEZ et al., 2006: 92-93).

Essas mudanças foram refletidas durante a gestão de Afrânio do Amaral. No relatório administrativo de 1932 entregue ao Departamento de Saúde Paulista, o médico defendeu a criação das seções de Botânica Médica, destinada ao cultivo e estudo de plantas medicinais, e de Fisiopatologia Experimental, com suas subseções de Fisiologia, Endocrinologia e Histo-Patologia, que demandariam aumento nos seus créditos anuais. Nesse contexto, a venda de plantas medicinais e de "preparados opoterápicos" oriundos da seção de endocrinologia "representariam fonte de recursos para o estabelecimento e, portanto, para o Estado" (RELATÓRIO ANUAL DO INSTITUTO BUTANTAN, 1938, p.9). A sinalização para a retomada dos trabalhos endocrinológicos e, em especial, da produção de opoterápicos destacava o potencial comercial desses produtos e sua participação na redução da crise financeira do instituto. Com esse intuito, a Seção de Fisiopatologia foi fundada em meados de 1934, tendo como assistente-chefe o Dr. Thales Martins (1876-1969) ${ }^{6}$. Após assumir a nova seção, Thales Martins iniciou os trabalhos investigativos sobre as glândulas endócrinas e "procurou orientar parte dos trabalhos para a produção de hormônios de aplicação terapêutica, como fonte de renda para o Instituto" (RELATÓRIO ANUAL DO INSTITUTO BUTANTAN, 1934).

Nesse cenário, as atividades registradas referentes à nova seção responsável pelas pesquisas com hormônios nos relatórios administrativos são descritas de maneira grandiloquente e guardam detalhes da rotina dos laboratórios, dos artigos científicos que foram elaborados e em quais periódicos foram publicados, bem como esmiúçam a rede de circulação de cientistas internacionais que por ali atuaram ou estiveram de passagem. Além disso, foram registradas listas de congressos científicos nacionais e internacionais onde a equipe de endocrinologia participou, os trabalhos apresentados e as parcerias que foram estabelecidas no exterior. Em que pese a não produção de opoterápicos durante sua gestão, Martins deu impulso considerável nos estudos de pesquisa "básica" sobre os temas hormonais, colocando, assim, a contribuição do IB para o campo da endocrinologia em escala transnacional. Destacam-se nesse período as pesquisas com hormônios sexuais, os estudos sobre a fisiologia do café e os variados estudos sobre as glândulas de secreção interna das cobras. ${ }^{7}$

\section{"São tantas as relações da Endocrinologia com outros ramos da ciência médica": uma breve trajetória do bócio no Brasil e a criação do Serviço de Endocrinologia e Assistência às Doenças Glandulares na década de 1940}

\footnotetext{
6 Thales Martins nasceu no Rio de Janeiro, em 29 de setembro de 1876. Doutorou-se em medicina, em 1919, na Faculdade de Ciências Médicas, da Praia Vermelha. Em 1925, sua amizade com os irmãos Ozório de Almeida ensejou alguns projetos, consolidados, no ano seguinte, com a entrada de Thales Martins nos quadros do Instituto Oswaldo Cruz. Em 1934, foi inaugurado o curso de fisiologia na Escola Paulista, ministrado por Martins. Desde então, o fisiologista atuou como pesquisador da Seção de Endocrinologia do Instituto Butantan. Suas pesquisas sobre a hipófise, bem como sua dedicação frente ao estudo do comportamento de animais sob os efeitos dos hormônios, destacaram-se no cenário nacional e internacional. Ver mais em VALLE, José Ribeiro do. Thales Martins: pioneiro da endocrinologia experimental. Arquivos Brasileiros de Endocrinologia e Metabologia, vol. 45, $n^{\circ}$. 5, supl. 2, nov. 2001, p.786-790.

7 Esse conjunto de publicações encontram-se publicadas nas Memórias do Instituto Butantan.
} 
As doenças relacionadas às disfunções da tireoide ocuparam lugar privilegiado na produção de conhecimentos e assistência clínica fornecida pelo Instituto Butantan, a partir de 1940. Convém destacar que os relatos sobre a presença do bócio no Brasil são abundantes na historiografia brasileira e remontam ao período colonial. Marques e Mitre (2004) exibiram o registro, elaborado pelo cirurgião barbeiro Luís Gomes Ferreira (1686-1764), que avistou inúmeros casos na capitania de Minas Gerais, para os quais prescreveu algumas receitas que constam no Erário Mineral (1735), editado em Lisboa. Outro registro da presença da doença do "papo" também foi cunhado pelo perito em assuntos estratégicos e da segurança da capitania de Minas Gerais, o sr. José Joaquim da Rocha, que ficou impressionado com a "grossura" dos pescoços dos brasileiros. Rocha escreveu em 1781 sua Geografia histórica da Capitania de Minas Gerais e relatou que na Correição do Rio das Mortes, onde situava-se a Vila de São João, que possuía ares sadios, um clima temperado e um pequeno número de doenças, a população local, sobretudo dos camponeses, exibia considerável "grossura" dos pescoços, também conhecida como "papos" e que a respiração destes ficava comprometida devido à doença (MARQUES; MITRE, 2004).

Já no século XIX, coube ao viajante naturalista Auguste Saint Hilaire (1779-1853), em sua primeira passagem pelo interior brasileiro, deixar os seus comentários sobre o bócio, enfatizando seu caráter endêmico, que atingia brancos e pessoas de cor e indicando que tal doença era ocasionada pela baixa temperatura da água. Típica da geografia médica predominante naquela época, a associação do bócio com as regiões montanhosas foi constantemente evocada. O engenheiro James Wells (1843-1903), por sua vez, em sua passagem pelo país em 1873, também indicou a presença da doença, quando passou pelas redondezas do rio Paraopeba, no centro de Minas Gerais, conhecida região endêmica do bócio no Brasil. Carl Friedrich Philipp Von Martius (1794-1868), igualmente, em 1820, verificou a existência da doença em diversas regiões que percorreu pelo Brasil, apontando o bócio e sua endemicidade nas margens do Paraíba (MARQUES; MITRE, 2004: 184).

Desde então, conforme assinalam Marques e Mitre, Minas Gerais continuou sendo ponto de passagem obrigatório daqueles que se interessavam pelo problema do bócio. No contexto das viagens aos sertões brasileiros, expressa na célebre anunciação de Miguel Pereira (1871-1918) em 1918 de que "o Brasil era um imenso hospital", o diagnóstico de que as populações interioranas jaziam em doenças insalubres e tropicais tornou-se símbolo de um país doente e que precisava ser higienizado e tratado sob o manto da medicina (HOCHMAN; MAIO; LIMA, 2010). Desse modo, Gilberto Hochman destacou que a identificação da tripanossomíase americana em 1909, por Carlos Ribeiro Justiniano das Chagas (1897-1934), pesquisador do IOC, limitou o debate sobre o bócio por três décadas. Em suas primeiras publicações, Chagas apontou que a fase crônica da doença de Chagas era marcada por distúrbios endócrinos, neurológicos e cardíacos. Na perspectiva inicial de Carlos Chagas sobre a doença que então descortinava, o mal de Lassance diferia dos casos europeus, pois se tratava de uma manifestação específica da tripanossomíase, e, portanto, a hipertrofia da tireoide era resultado da ação do parasito Tripanosoma no organismo. Essa tese ficou conhecida pelo termo “tireoidite parasitária”(CHAGAS, 1911). Assim, o bócio passou a constar na agenda de pesquisa dos saberes em doenças tropicais e da parasitologia, em período marcado pela efusividade de pesquisas e de caças intermináveis aos micróbios (KROPF, 2009a).

Como consequência dos estudos inovadores de Carlos Chagas sobre a tripanossomíase americana, o problema do bócio tornou-se um dos temas mais discutidos no âmbito da classe médica e da saúde pública nacional (KROPF, 2009). Nesse contexto, podemos indicar que, indiretamente, as correlações entre a Doença de Chagas e o quadro tireoidiano reforçaram no debate médico e social a importância dos temas endocrinológicos e das funções da tireoide, seja em seus 
quadros de hiper ou hipofunção glandular. Conforme destacou Kropf, Chagas estava ciente de que os distúrbios da tireoide provocavam uma série de comprometimentos físicos e neurológicos dos indivíduos, e com essa mirada enfatizou a relevância médico-social da doença, como "condição mórbida crônica que inutiliza o indivíduo para a atividade vital" e como "um fator importante de degeneração humana". Os distúrbios ${ }^{8}$ endócrinos da fase crônica foram classificados por Carlos Chagas de acordo com a intensidade e foram divididos em duas expressões clínicas: a pseudomixedematosa e mixedematosa. A primeira compreendia a maioria dos portadores da infecção, visto que eram crianças e jovens que sobreviveram à fase aguda da doença e sofriam dos efeitos ainda leves do hipotireoidismo. Nestes, o papo era incipiente e não era assustador, como apresentavam os adultos depois de viverem a fase progressiva da doença. Já a segunda forma, a mixedematosa, abarcava os casos menos comuns de maior gravidade do comprometimento da tireoide. Não possuindo a hipertrofia da glândula, possuíam a tireoide atrofiada, cuja função destruída resultava em efeitos extremamente debilitantes. Com esses dados, Chagas realizou constantes denúncias sociais dos efeitos físicos e sociais da doença, pois seus portadores eram "criaturas condenadas à existência de monstros" (KROPF, 2009,p.136-139).

No entanto, a dificuldade em comprovar histologicamente a presença do patógeno T. cruzi consolidou uma intensa controvérsia científica envolvendo argentinos e brasileiros. ${ }^{9}$ Kropf sustenta que Carlos Chagas conduziu um "reenquadramento" no desenho clínico da tripanossomíase, minimizando a primazia dos sinais tireoidianos e reforçando a importância dos elementos cardíacos (KROPF, 2009, p. 213).

Por essas razões, pesquisas sobre o bócio endêmico em Minas Gerais e outras regiões interioranas do país passaram a ser largamente documentadas nas primeiras décadas do século XX. Lobo Leite, na década de 1930, relatou à Sociedade Brasileira de Biologia os resultados de suas pesquisas em Conselheiro Lafaiete e Ouro Preto, onde alegou a não correlação entre a tripanossomíase americana e o bócio endêmico encontrado em municípios mineiros. Em 1936, foi a vez de Artur Penna de Azevedo publicar sua "Histologia Pathologica da glândula thyreoide na fórma chronica da doença de Chagas (Trypanosomose americana)", cujo estudo foi realizado com base em 26 casos de autópsias de moléstia de Chagas, de pacientes registrados na Seção de Anatomia Patológica do Instituto Oswaldo Cruz. A maioria do material analisado provinha de Lassance, Minas Gerais. Algumas amostram também foram obtidas em hospitais do Rio de Janeiro, coletadas pelos médicos Magarino Torres e Burle de Figueiredo (AZEVEDO, 1936).

Desse modo, a constante produção de pesquisas sobre o bócio contribuiu para o reconhecimento do cretinismo como uma das principais doenças presentes no território brasileiro e diretamente relacionada às disfunções tireoidianas. Desse modo, a dimensão clínica do cretinismo congênito esteve presente tanto na abordagem da clínica endocrinológica quanto nos estudos de nutrição, visto que se tratava de uma doença fortemente vinculada aos aspectos hereditários e

\footnotetext{
8 Chagas subdividiu a fase crônica da doença em cinco aspectos clínicos, sendo: 1- sinais pseudomixedematosos; 2- casos mixedematosos; 3- forma nervosa; 4- casos cardíacos; 5- incidentes agudos e subagudos (KROPF,2009,p.138).

9 O imbróglio e lento movimento da dissociação da relação Tripanossoma cruzi e bócio ocorreu durante a década de 1940 e permitiu, conforme salientou Hochman (2010b), ensejar ações como a da Comissão de Mobilização Econômica, órgão relacionado ao escopo de guerra brasileiro no Estado Novo, que decretou, em setembro de 1942, a obrigatoriedade da iodação do sal consumido em regiões onde era constatada sua endemicidade, a saber, os estados de Minas Gerais e Goiás. 0 decreto sofreu pressão e foi impedido de prosseguir, sob a alegação colocada de que o Instituto Nacional do Sal (INS), por ser este órgão governamental, tinha fins de incentivar o setor salineiro e que contava com os interesses dos donos das salineiras em seu séquito.
} 
expressão do aspecto crônico de uma anomalia que resultava em prejuízos severos ao desenvolvimento psíquico, corporal e nutricional das crianças. Claude Olivier Doron (2011) enfatizou o papel que o cretinismo desempenhou na consolidação da teoria da degeneração no século XIX, posto que, por se tratar de uma doença hereditária, foi relacionada com a noção de incurabilidade. Conhecido pela topografia médica desde o século XVIII, o cretinismo dos habitantes dos Alpes e dos Pireneus tornou-se doença marcante no discurso antropológico e patológico que pensava as fronteiras da degeneração das espécies com base na exibição de "raças distintas". A rigor, o tratado sobre as degenerações de Charles Benedict Morel deve ser lido, conforme pontua Doron, como resultado de seus investimentos iniciais sobre o cretinismo em seus primeiros escritos, nos quais a influência da constituição geológica na produção da endemia de bócios permitia acompanhar um modo especial da ação e produção da degeneração da espécie humana, sendo o cretinismo o ponto mais alto da classe dos degenerados (DORON, 2011, p. 942-943).

Desde o século XIX, algumas doenças tornaram-se representativas do retardo mental e degeneração, dentre elas convém destacar os "mongoloides", os "feeblemindedness" e o cretinismo. Nesse cenário, a associação das disfunções tireoideanas como causas do cretinismo, durante o início do século XX, trouxe efeitos contraditórios no entendimento daquela que foi considerada como uma das expressões de idiotia mais recorrentes, isto é, o mongolismo. De acordo com Lowy (2017), um dos primeiros efeitos foi a dissociação do cretinismo com o mongolismo, visto que, quando um “feeble-minded" apresentava melhoramento após o tratamento com extrato de tireoide, o paciente era enquadrado como portador de cretinismo. O segundo resultado reforçou que o mongolismo era uma desordem metabólica, provavelmente induzida pelo desequilíbrio hormonal e, assim, passível de tratamento. Clemens Benda (1898-1975) foi um dos maiores defensores de que o mongolismo constituía uma desordem metabólica hormonal ocasionada antes do nascimento. Publicado em 1938, seu artigo Mongolism and Cretinism: A Study of the Clinical Manifestations and the General Pathology of Pituitary and Thyroid Deficiency defendia que o mal desenvolvimento do cérebro ocorria no ciclo embriônico, provavelmente na $18^{a}$ semana de gravidez, quando colidiam com as perturbações da secreção pituitária e tireoidiana da gestante, responsáveis por restringir as crianças de absorverem os nutrientes essenciais para o processo de formação do desenvolvimento cerebral. Entretanto, esta visão perdurou até 1959, quando o mongolismo foi definitivamente identificado como uma anomalia oriunda da trissomia 21, cópia adicional do cromossomo 21 (LOWY, 2017, p.34-36).

Foi nesse contexto de crescente reconhecimento da presença das doenças endocrinológicas no Brasil que o decreto estadual $n^{\circ} .11 .032^{10}$, promulgado em 16 de abril de 1940, transformou a Seção de Fisiopatologia Experimental do Instituto Butantan em Seção de Endocrinologia. A nova locação especializada nas pesquisas e fiscalização de produtos hormonais foi estabelecida no Pavilhão João Florêncio, no Instituto Butantan. Inaugurada em 30 de julho de 1940, o evento contou com a presença do diretor e funcionários do instituto, de membros da classe médica paulista e do então interventor federal, Adhemar de Barros (1901-1969). Desde então, as atividades da nova seção funcionaram em dois ambientes, sendo a parte experimental fixada no Instituto Butantan e

\footnotetext{
10 Além do incentivo à investigação experimental da fisiologia e patologia das glândulas de secreção interna, foi delegada à nova seção a tarefa de investigar "as correlações entre as degenerações orgânicas, a criminalidade e as tendências antissociais, por um lado, e os distúrbios endócrinos, por outro”. Convém destacar que não foram encontradas evidências que permitam afirmar que a nova seção de Endocrinologia do IB tenha produzido conhecimentos nesse sentido. A rigor, foi possível inferir em pesquisa anterior que Thales Martins defendeu o afastamento dos saberes hormonais da endocriminologia. Ver mais em LIMA,2016. Para acompanhar a inserção da criminologia no âmbito da endocrinologia, ver mais em OLIVEIRA JÚNIOR, 2012.
} 
a área clínica, localizada em duas salas no Centro de Saúde Santa Cecília, na rua Victorino Carmillo. O consultório contava com instrumentos para mensuração do metabolismo basal, máquina fotográfica, fichários para fomentar um arquivo de observações e serviço de raio x, elemento vital para o diagnóstico da idade óssea dos pacientes.

Figura 2: Paciente infantil portadora de cretinismo congênito/ Child patient with congenital cretinism.

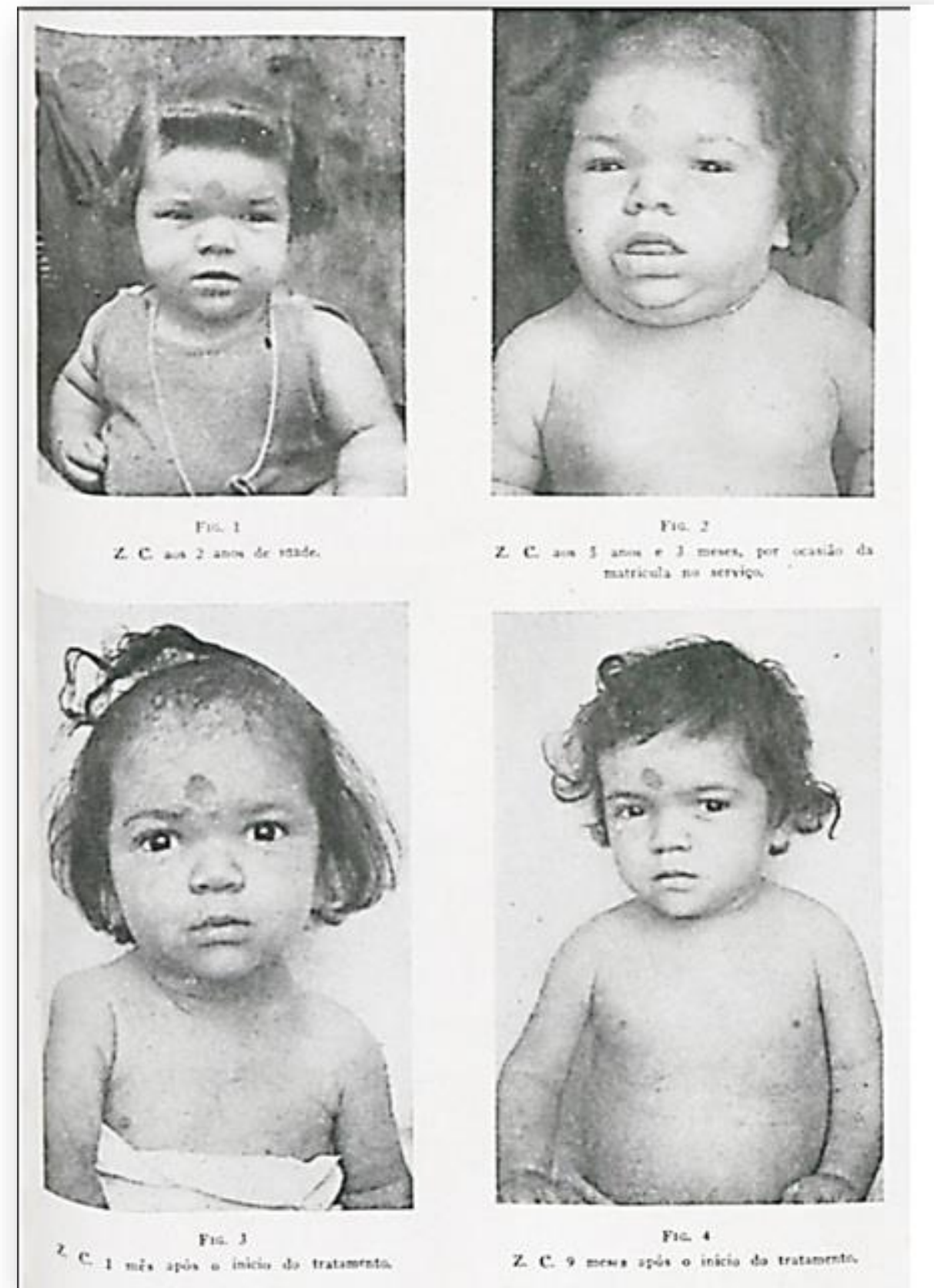

Paciente com cretinismo congênito tratada pelo Serviço de Endocrinologia Humana do Instituto Butantan. Sobre o desenvolvimento do caso e de outros pacientes, ver mais em: LOBO,José Ignácio; DÉCOURT, Luciano.Alguns aspectos da evolução do cretinismo e do mongolismo. Memórias do Instituto Butantan, Tomo XVI, 1942. Disponível em: < > Acesso em: [ 29 out. 2019].

É preciso registrar que a fundação do Serviço de Endocrinologia no Instituto Butantan é 
coetânea à promoção de iniciativas focadas para a melhoria da alimentação da população, durante o governo Vargas, onde as doenças de secreção interna tornaram-se uma questão social e adentraram na agenda das políticas públicas de saúde do Estado Brasileiro, visto que foi fundado uma Clínica das Doenças de Nutrição e Glândulas de Secreção Interna no Instituto de Aposentadorias e Pensões dos Industriários, fundado em 1936. Naquela altura, ganhavam adesão pública os debates relacionados à fome e muitos dos intelectuais engajados na luta contra as doenças carenciais iniciaram suas atividades clínicas a partir da residência médica em endocrinologia e nutrologia. ${ }^{11}$ Este direcionamento estatal também pode ser observado por meio da fundação de restaurantes populares subsidiados, como o Serviço de Alimentação e Previdência Social (1940), restaurantes nas empresas, refeições para alunos de escolas públicas das grandes cidades e incentivo a pesquisas sobre alimentos, situação alimentar e educação nutricional (HOCHMAN, 2010,p.168).

Por essas influências, compreende-se que um dos pontos caros à Seção foi o "aspecto demográfico que a Endocrinologia possa oferecer", posto que atuaria na coleta de dados sobre as recorrências de doenças glandulares em populações específicas, realçando as "causas mesológicas que sobre elas interfiram", de modo que as relações entre as doenças ocasionadas por disfunções nas glândulas de secreção interna também fossem correlacionadas com os "distúrbios nutritivos ocasionados por deficiência na alimentação” (RELATÓRIO ANUAL DO INSTITUTO BUTANTAN, 1941,p.361-362). Nesse sentido, a prioridade no atendimento era concedida aos pacientes portadores de doenças endocrinológicas, o que não impedia que a assistência fosse concedida a outros casos. Os pacientes matriculados passaram a contar com observação minuciosa de seus casos, sendo solicitados exames complementares e fotografias registradas. Após a coleta dos dados clínicos, os casos eram discutidos em reuniões semanais, enquanto os antigos "sempre revistos através da ficha de evolução" (Ibidem, p.362).

\footnotetext{
11 Durante a década de 1920, Josué de Castro, renomado intelectual sobre a fome no Brasil, realizou estudos no Instituto Municipal de Nutrición de Buenos Aires, única instituição especializada em nutrologia no cenário sul-americano, liderada pelo renomado nutricionista argentino Pedro Escudero (1887-1963) (BRINKMAN, 2013). Outrossim, entre 1930 e 1935, conforme assinalou Vasconcelos (2001, p.323-328), Josué de Castro iniciou o exercício da medicina nos ramos da nutrição e endocrinologia, paralelamente às suas funções na docência de Fisiologia na Faculdade de Medicina do Recife e à publicação de seus primeiros escritos. Outro caro personagem é o médico pernambucano Nelson Chaves, que exerceu entre 1932 e 1941, em sua clínica particular, práticas médicas relacionadas à nutrição e à endocrinologia. Destacou-se em 1932 pelos seus primeiros artigos científicos, que versavam sobre o cretinismo endêmico, hipertireoidismo e artrite pulmonar, em periódicos recifenses. Três anos depois, foi publicado seu Tratamento médico do hipertireoidismo. Ver mais em: KROPF, 2013; BEZERRA, 2012; BRINKMANN, 2013; VASCONCELOS, 2001.
} 
Figura 3: Prédio Central da Seção de Endocrinologia/ Endocrinology Section Central Building - 1940

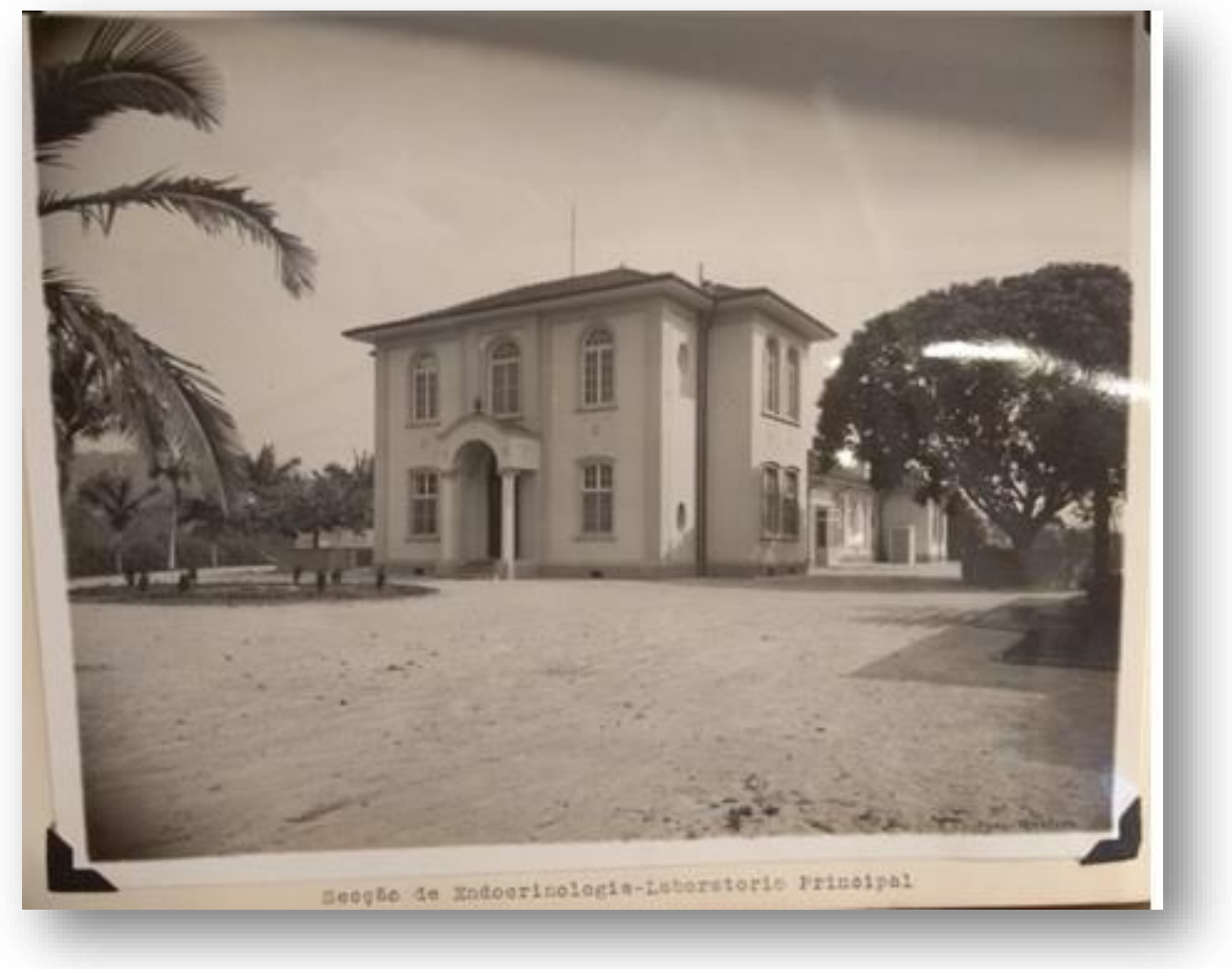

Fonte: RELATÓRIO ANUAL DO INSTITUTO BUTANTAN, 1940, p. 20. Acervo Instituto Butantan/ Centro de Memória. São Paulo, Brasil.

Outrossim, cumpre destacar que o Serviço de Endocrinologia Humana do Instituto Butantan pode ser considerado como catalisador do retorno das produções hormonais na instituição dedicadas ao tratamento da diabetes. Devemos enfatizar a originalidade das produções farmacêuticas ali elaboradas que ganharam a pauta do debate sobre o tratamento das doenças de má-formação congênita das crianças. No âmbito produtivo, encontramos a elaboração do Prolactin, "hormônio galatogênico prehipofisário" e a "Tireotrofina", extraída do lobo anterior da hipófise, ambas utilizadas para fins experimentais, sendo a primeira utilizada em ensaios com pombos. ${ }^{12} \mathrm{Na}$ clínica, os casos de diabete insípido foram tratados com o tanato de pitrassina e o pó de lobo posterior da hipófise. Por outro lado, foi destacado que as preparações visavam suprir as experiências e o tratamento de "casos especiais". Para ampliar o seu aspecto comercial, foi demandado investimentos em instalações adequadas, contratação de pessoal e pesquisas sobre as obtenção da matéria-prima. Para o relator, o Instituto deveria operar somente como órgão regulador das atividades privadas e não atuar como concorrente destas; a exceção se daria somente nos casos em que houvesse fornecedores que não dominassem as melhores aparelhagens e técnicas de produção, de modo a fornecer bioterápicos de qualidade para a Saúde Pública (RELATÓRIO ANUAL DO INSTITUTO BUTANTAN, 1940.p.152).

\footnotetext{
$12 \mathrm{~A}$ aproximação com as indústrias privadas fornecedoras de bioterápicos também emerge nas páginas do relatório, num indício que aponta para a permuta de produtos hormonais entregues para a realização de experiências, como a "Regulação hormonal da Genitália Masculina", projeto que foi iniciado em 1937 e que contou com a participação das empresas Ciba, Merck, Laboratório Silva-Araújo-Roussel e Parke \& Davis (RELATÓRIO ANUAL DO INSTITUTO BUTANTAN, 1940,p.153).
} 
Figura 4: Laboratório da Seção de Organoterapia/ Organotherapy Section Laboratory.

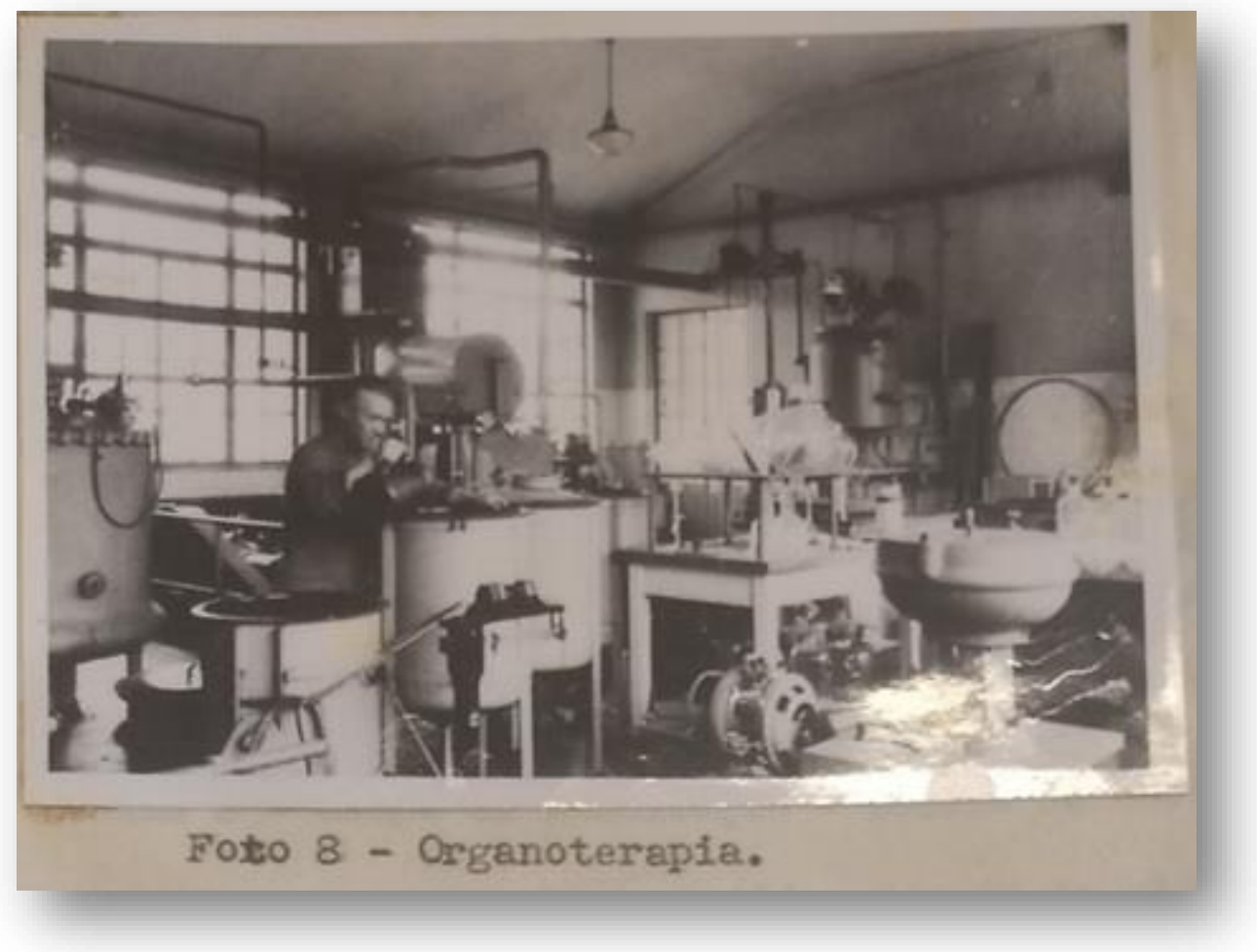

Fonte: RELATÓRIO ANUAL DO INSTITUTO BUTANTAN, 1940. p.247. Acervo Instituto Butantan/ Centro de Memória. São Paulo, Brasil.

No entanto, mesmo sob o cenário de crises constantes e falta de funcionários especializados, foi possível fornecer ao almoxarifado do Instituto Butantan um medicamento inovador. Concebido pelo diretor da Seção de Endocrinologia, o farmacologista José Ribeiro do Valle ${ }^{13}$, foram produzidos em 1940 cerca de 1.120 papéis de 20mg de "Pó de Lobo Posterior de Hipófises Bovinas", aplicado no tratamento do diabetes insípido, por via nasal (RELATÓRIO ANUAL DO INSTITUTO BUTANTAN, 1941, p.366). Para Valle, a eficácia do produto foi "determinada com vigor no Serviço de Endocrinologia Humana", daí o interesse de médicos pelo produto. Desse modo, o conjunto de possibilidades produtivas não cessava:

Outro produto que a Parte Clínica carece com relativa urgência, pois que os bons preparados de origem alemã existentes na praça já se esgotam, é o "Pó de Tireóides" para o tratamento do hipotiroidismo e do mixedema. Os estudos realizados no ano passado e que ainda prosseguem estão em sua fase final. Foram estudadas 10 preparações in anima mobile, obtidas com diversas técnicas, e somente uma mostrou atividade aceitável nas dosagens clínicas administradas. Não se trata de complicações irremovíveis no preparo, mas simplesmente das condições da matéria prima. Para a obtenção deste produto em escala comercial, entretanto, se fazem necessárias instalações e aparelhagens apropriadas (IDEM, p.367).

13 José Ribeiro do Valle (1908-2000) nasceu em Guaxupé, Minas Gerais. Em 1932, graduou-se na Faculdade de Medicina de São Paulo. Dois anos depois, foi conduzido à Escola Paulista de Medicina, por meio de Otto Bier e André Dreyfus, onde inaugurou a escola de Farmacologia e a experimentação animal. Desenvolveu diversas pesquisas durante sua permanência enquanto assistente do Serviço de Fisiopatologia do Instituto Butantan, durante a gestão de Thales Martins. Com a saída deste, assumiu a gestão do Serviço de Endocrinologia, fundado em 1940. Realizou estágios internacionais em centros renomados de pesquisa. Ver http://www2.unifesp.br/dfarma/valle.html. 
Corroborando a assertiva de Raj (2013), segundo a qual durante o processo de circulação de conhecimentos, estes podem ser negociados, transformados e adaptados nos diferentes contextos locais de sua inserção, podemos enunciar que a produção de hormônios no IB ressignificou a produção dos extratos glandulares em período posterior às sintetizações hormonais, ocorridas na década de 1930. É o que demonstra o relatório administrativo, de 8 de maio de 1942, onde o farmacêutico José Ribeiro do Valle enviou ao diretor informações a respeito do "Pó de Lobo Posterior da Hipófise", que vinha demonstrando bons resultados na área clínica e era "ultimamente vendido por este instituto". A prescrição era para casos de diabete insípido e, reconhecendo a "raridade da afecção", seu uso deveria ser limitado, mas, mesmo assim, a "procura do produto excedeu a expectativa". Com isso, Valle delineou os caminhos para que fosse produzido uma melhor embalagem para o produto e uma redação da bula do medicamento, inserida no relatório (RELATÓRIO ANUAL DO INSTITUTO BUTANTAN, 1942, p1-2). Não obstante, as doenças relacionadas com o quadro da tireoide também foram alvo das pesquisas no serviço de Endocrinologia Humana e, por esses motivos, experiências com homens foram realizadas com uso da"Prolactina" e do "Hormônio Tireotrópico", num total de 100 ampolas. Paralelamente, a iodotiroglobulina foi produzida (ibidem, p.469).

O pó de lobo posterior de hipófises bovinas era preparado segundo o método descrito pela Farmacopéia Americana, contendo princípios oxitócico, vasopressor, antidiurético e melanofórico. Para o uso integral de suas atividades, era vital seu acondicionamento em ampolas fechadas a vácuo. No mesmo ano, no relatório geral dos serviços apresentado pelo diretor Flavio da Fonseca, foram produzidos 6.580 papéis de lobo posterior de hipófise e 3.951 comprimidos de tireoide (IDEM, p.15). No ano seguinte, o movimento do serviço contou com 82 matrículas novas, 1754 consultas, 554 injeções aplicadas 245 exames, dos quais 109 eram hormonais e 85 radiografias (IDEM, p. Incompreensível ). Em depoimento concedido à Simon Schwartzman, José Ribeiro do Valle relatou o processo em torno da elaboração do Pós-Fitan:

\footnotetext{
Há uma doença que se chama diabete insípido - a pessoa urina à bessa e bebe água à bessa. É um tonel de (?). Havia doentes que exerciam a profissão quase que incompatível com a doença. Havia um motorneiro que, em cada parada do bonde, corria ao bar, urinava e bebia um copo d'água. Naquele tempo havia um tratamento interessante que era o pó de hipófise, do lobo superior da hipófise: você pega a hipófise de animais de matadouro, tira o lobo superior da hipófise, faz um pó acetônico - um pó bem fininho - e, aspirando aquele rapé, regula a emissão de urina e o sujeito passa a viver com mais tranquilidade. Isso foi um sucesso. Para toda diabete insípido que havia, iam lá buscar o nosso pó. Chamávamos de pó de pirlimpimpim. Este é um exemplo do conhecimento que influenciava a parte clínica endocrinológica do Butantã. A tireoide, por exemplo. Crianças com subdesenvolvimento, com mixedema, meio idiota, passavam a receber o pó de tireoide. Preparávamos no laboratório, ensaiávamos e dávamos (VALLE,2010, p.23).
}

A elaboração do Pós Fitan ou "pó de pirlimpimpim" é um bom exemplo da transformação das terapias hormonais no contexto local paulista. De acordo com Valle, os hormônios do crescimento one two three, elaborados pela Companhia Parke and Davis, que foram injetados em "meninos nanicos", não funcionavam. Segundo o farmacologista, a compreensão de que os hormônios de hipófise de animais de matadouros não eram eficientes em homens não estava estabelecida naquele momento e, por isso, quando da concessão de seu depoimento, deixou registrado que somente a hipófise de humanos serviria para esse objetivo, e, daí em diante, "as hipófises de cadáveres 
passaram a ser uma matéria prima importante" ${ }^{14}$ (Idem).

Nesse âmbito, doenças metabólicas raras ocuparam lugar de destaque no quadro das pesquisas em endocrinologia dos pesquisadores do Instituto Butantan, especialmente aquelas relacionadas ao quadro infantil.

Há os chamados équus infantis- os meninos ou meninas que começam a se desenvolver e aos quatro anos de idade são verdadeiros touros. Isto é devido a um tumor da suprarrenal e para diagnosticar esses tumores há um exame de urina que detecta uma quantidade enorme de hormônios. Fazíamos isso lá. Muitos casos foram exemplo de um interesse muito grande entre uma parte básica envolvida na pesquisa básica e a sua aplicação quase que imediata (VALLE, 2010,p.24).

Em seguida, José Ribeiro do Valle indicou que as significativas transformações vivenciadas pelo IB em 1945 repercutiram no Laboratório de Endocrinologia, visto que suas instalações foram fragmentadas e transferidas para o Hospital Vital Brazil ${ }^{15}$, nomeadamente, seu laboratório clínico, hormodiagnóstico e histologia. Para o prédio central foram alocadas as seções de endocrinologia experimental e bioquímica. Devido às mudanças, não foram realizados cursos externos, conferências e trabalhos de divulgação naquele ano. Desde então, os profissionais graduados do laboratório do Instituto Butantan passaram a atuar na licenciatura da Escola Paulista de Medicina.

Dessa forma, por meio do acervo investigado, visualizamos o crescimento da seção de endocrinologia expresso no levantamento de sua produção científica. Em 1941, o laboratório dos hormônios ocupou o primeiro lugar no conjunto dos trabalhos publicados e encaminhados para publicação, o que assinala para uma conjuntura favorável no serviço experimental, bem como para a elaboração de pesquisas com fins de publicação e inserção dos pesquisadores do IB no cenário da comunidade científica transnacional. ${ }^{16}$ Acrescem a esse circuito as participações dos membros do Instituto de Endocrinologia e de outros médicos do país no $2^{\circ}$ Congresso Pan-Americano de Endocrinologia, realizado em Montevidéu, em março de 1941, resultando numa intensa circulação de cientistas, promoção de acordos, envio dos artigos comunicados para cientistas de diversos países (IDEM).

Assim, o acervo documental desta instituição viabiliza considerar que doenças como o bócio, cretinismo, nanismo e diabetes receberam considerável atenção dos cientistas ligados à análise clínica das endocrinopatias da população paulista, bem como as fontes possuem conteúdos raros que descrevem os meandros de seu cotidiano, como o registro quantitativo dos pacientes ali internados, dos exames hormonais realizados e das injeções hormonais aplicadas. Ademais, é possível

\footnotetext{
14 Prescott também trouxe informações significativas a respeito da produção de extratos hormonais no âmbito norte-americano e apontou a criação do Hospital de Endocrinologia fundado na John Hopkins University, em 1935, onde foram promovidas pesquisas com o hormônio do crescimento (GH) elaborado com extratos de pituitária de cadáveres. Dada a influência destes extratos no cenário da assistência endocrinológica pediátrica, foi fundada em 1960 a National Pituitary Agency, formada por endocrinologistas, pediatras, cientistas e administradores pertencentes ao National Institute for Arthritis and Metabolic Diseases. O objetivo desse órgão era coordenar a extração e distribuição de GH. Assim, o cenário norte-americano conviveu com uma longa história do uso destes extratos até a década de 1980, quando, através das técnicas de DNA recombinantes, se chegou à síntese do hormônio (PRESCOTT, 2000).

15 O Hospital Vital Brazil foi instalado em 1945, no prédio do antigo diretor do Instituto Butantan. Contava com 15 leitos, 2 quartos particulares, laboratório, biotério, raio-X e sala para consultas. Sua direção estava sob a coordenação de José Ignácio Lobo (RELATÓRIO ANUAL DO INSTITUTO BUTANTAN, 1945).

16 No primeiro semestre de 1941, o Dr. José Ribeiro do Valle, após análise de títulos, recebeu uma bolsa de estudos para pesquisar na Guggenheim Memorial Foundation (RELATÓRIO ANUAL DO INSTITUTO BUTANTAN, 1941, p.468).
} 
localizar a programação de cursos de endocrinologia realizados pela instituição e que assinalam para um processo de formação contínua de novos especialistas. Por fim, convém mencionar a presença do modelo de ficha de prontuário elaborado pela clínica do Serviço de Endocrinologia Humana e a conservação de fotografias de portadores de nanismo, cretinismo, mixedema e hipogonadismo capturadas durante o processo de observação dos pacientes ${ }^{17}$.

Figura 5: Bula Prescritiva Pós-Fitan/ Post-Fitan Prescription Bull.

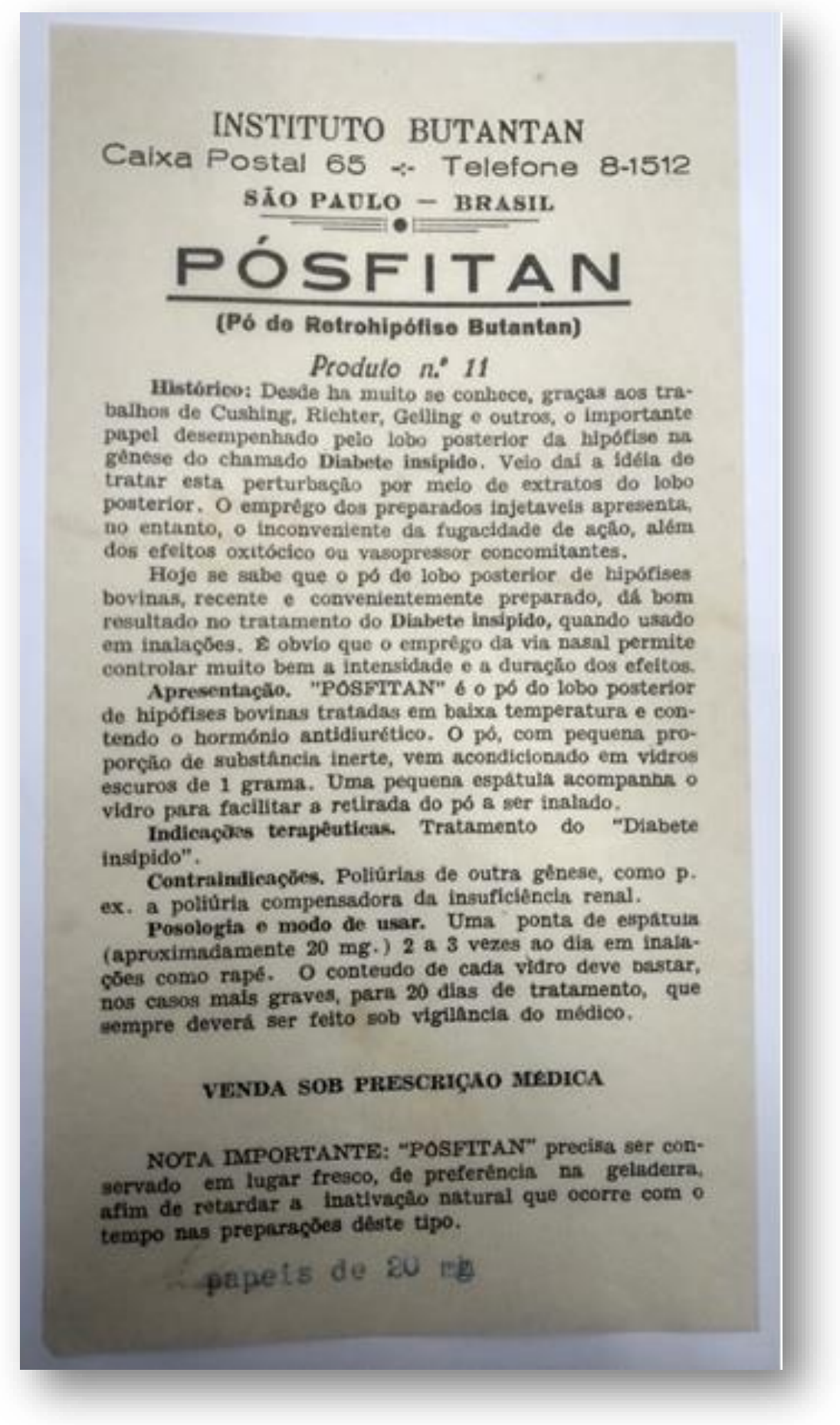

Fonte: Caixa:1019. Acervo Instituto Butantan. Centro de Memória. São Paulo, Brasil.

17 Algumas destas fotos foram publicadas em artigos publicados nas Memórias do Instituto Butantan. 


\section{Conclusão}

Como vimos, a análise da produção de opoterápicos permite refletirmos sobre a inserção das terapêuticas hormonais no contexto da emergência histórica das doenças endocrinológicas como questão de saúde pública, nas primeiras décadas do século XX, na capital paulista. Com a entrada de Arthur Neiva na direção do Instituto Butantan em 1919, o campo das produções organoterápicas recebeu considerável impulso, posto que o potencial econômico desta classe de medicamentos, além de ser atraente, consolidou, igualmente, interesses de pesquisas na produção de conhecimentos e medicamentos hormonais, cujas experiências foram obtidas em clínicas diversas e não restritas ao Instituto Butantan. Outrossim, cumpre assinalar para um passo historiográfico importante aqui registrado - recentemente indicado por Duarte (2019) sobre a participação dos matadouros e açougues no âmbito da História Ambiental e aqui observado sob a ótica da História das Ciências e da Saúde -, relacionado à expressiva presença de parcerias e trocas entre o Instituto Butantan com diversos matadouros e fornecedores de órgãos de animais, destinados à produção de extratos, injeções e comprimidos hormonais. Assim, estes dados motivam vislumbrar no porvir instigantes vias de investigações históricas, quais sejam: o papel dos animais não humanos como coparticipantes na produção de terapêuticas médicas, de um lado, e o crescente papel das discussões médicas frente ao grupo das doenças endocrinológicas nas primeiras décadas do século XX, no Brasil.

Paralelamente, argumento que a tripanossomíase americana identificada em Lassance e o conceito de tireoidite parasitária evocado por Carlos Chagas, em 1909, lançaram dilemas e ressaltaram no cenário médico brasileiro a importância das doenças relacionadas à tireoide, movimento este perceptível em estudos publicados nos anos seguintes frente ao problema do bócio endêmico e cretinismo em diversas regiões do Brasil. Consideravelmente beneficiada pela divulgação das controvérsias face à presença da tireoide no quadro clínico da parasitose causada pelo barbeiro, a endocrinologia tornou-se campo disciplinar atraente para estudantes de medicina, cujo conjunto de desordens metabólicas oriundas dos estágios de hipo e hiper função das glândulas de secreção interna demandou constante especialização da comunidade médica sobre os saberes hormonais e olhar clínico habilitado para reconhecer e discernir a complexa relação das doenças endócrinas com demais órgãos e os fatores de seu desenvolvimento, como a alimentação, aspectos hereditários e condições etárias específicas.

Pelo exposto, corroboramos que a dinâmica da produção de opoterápicos envolveu interesses comerciais substanciais, capazes de interromper a elaboração de preparados hormonais no Instituto Butantan em 1925, em função do risco que apresentava para a concorrência das indústrias privadas. Não obstante, com o revigoramento das políticas de incentivo à produção científica e intelectual no período varguista, a retomada dos trabalhos em endocrinologia e a fundação da Seção de Fisiopatologia Experimental em 1934, podem ser interpretadas como indicadores de uma próspera fase de investimentos em estudos científicos e produção de conhecimentos sobre os hormônios sexuais, publicados nos principais periódicos científicos nacionais e internacionais de fisiologia e endocrinologia. Certamente, estudos históricos vindouros que versem sobre o impacto das publicações científicas realizadas neste período, bem como das contribuições destes saberes na formação de novos especialistas em endocrinologistas, em diversas regiões do país, poderão enriquecer nosso entendimento sobre o processo de recepção e circulação dos conhecimentos, técnicas e contribuições brasileiras originais para o cenário transnacional das pesquisas com hormônios, durante a primeira metade do século XX. Como exemplo, vale lembrar que o estudo das aplicações 
de hormônios sexuais em cães realizadas pelos cientistas da Seção de Endocrinologia do Instituto Butantan, em 1941, recebeu o prêmio da Sociedade Norte-Americana de Psicologia Experimental. Assim, avaliar o impacto do estado da arte dos estudos do behaviorismo animal, por volta daquela época, quando submetidos aos hormônios renderia reflexões caras aos estudos sobre circulação dos conhecimentos científicos locais e sua interação com o cenário global.

Doravante, a análise da produção de fármacos destinados ao tratamento de pacientes com endocrinopatias e a fundação do Serviço de Endocrinologia Humana no Instituto Butantan em 1940 permitiram demonstrar o reconhecimento histórico e médico-social das doenças endócrinas como problema de saúde pública, na capital paulista. Desde então, a promoção de assistência e atuação dos cientistas alocados no IB no tratamento dos casos clínicos de cretinismo, bócio, infantilismo, nanismo, hipogenitalismo, puberdade precoce, dentre outras, expressa uma continuidade histórica da ciência brasileira no tratamento das populações doentes que, sob o crivo da medicina, poderiam ser reabilitadas e tratadas com terapias hormonais variadas. Desde a utilização de extratos de tireoide nos casos de cretinismo aos usos do inovador pó de pirlimpimpim no tratamento das diabetes, constata-se que a produção de conhecimentos sobre os hormônios caminhou pari passu ao desenvolvimento de terapias encaminhadas às clínicas médicas brasileiras, das quais pouco sabíamos e muito poderemos saber futuramente. De sorte que estas vias constituem-se como importante conteúdo a ser somado na historiografia que versa sobre a especialização da endocrinologia no Brasil, bem como contribuem para ampliarmos a compreensão da história do Instituto Butantan. Para os pesquisadores, a tarefa não poderia ser mais estimulante.

\section{Referências \\ Fontes Primárias}

AZEVEDO, Artur Penna de. Histologia pathologica da glandula thyreoide na fórma chronica da doença de Chagas (Trypanosomose americana). Rio de Janeiro: Canton \& Reile, 1936.

BULA PRESCRITIVA PÓS-FITAN. Caixa:1019. Acervo Instituto Butantan. Centro de Memória.

CHAGAS, Carlos. Moléstia de Carlos Chagas ou thyreoidite parasitaria: nova doença humana transmitida pelo barbeiro (Conorhinus megistus). Revista Médica de São Paulo, 14(18), 1911, pp. 337 356.

INSTITUTO VITAL BRAZIL. Catálogo com indicações sobre a aplicação de alguns dos produtos do Instituto. São Paulo. 1920.

LOBO, José Ignácio; DÉCOURT, Luciano. Alguns aspectos da evolução do cretinismo e do mongolismo. Memórias do Instituto Butantan, Tomo XVI, 1942. Disponível em: <https://bibliotecadigital.butantan.gov.br/edicao/memorias-do-instituto-butantan-tomo-xvi-1942/253>. Acesso em: [ 29 out. 2019].

PRODUTOS DE N. 100-101. BULAS-1B-CX 0542. 1918. Acervo Instituto Butantan. Núcleo de Documentação. São Paulo. Brasil.

RELATÓRIOS ANUAIS DO INSTITUTO BUTANTAN. 1917-1945. Acervo Instituto Butantan/Centro de Memória. São Paulo. Brasil.

SÃO PAULO (Estado). Decreto n. 11.032, de 16 de abril de 1940. Lex: Transforma, no Instituto Butantã, a Seção de FisioPatologia Experimental, em Seção de Endocrinologia [...], São Paulo, 1940.

\section{Fontes Secundárias}

BECALOSSI, Chiara. Italian sexology, Nicola Pende biotypology and hormone treatments in the 1920s. 
Histoire, médecine et santé, n. 12, 2018, pp. 73-97.

BENCHIMOL, J.; TEIXEIRA, L. A. Cobras, lagartos e outros bichos: uma história comparada dos institutos Oswaldo Cruz e Butantan. Rio de Janeiro: Editora da UFRJ, 1993.

BEZERRA, José Arimatea Barros. Educação alimentar e a constituição de trabalhadores fortes, robustos e produtivos: análise da produção científica em nutrição no Brasil, 1934-1941. História, Ciências, Saúde - Manguinhos, Rio de Janeiro, v. 19, n. 1, jan.-mar. 2012, pp. 157-179.

BORELL,Merry Origins of the hormone concept: internal secretions and physiological research, 1889-1905. Tese (Doutorado em História), Yale University, 1976.

BRINKMANN, Sören. Leite e modernidade: ideologia e políticas de alimentação na era VARGAS. História, Ciências, Saúde - Manguinhos, Rio de Janeiro, 2013.

CUETO, Marcos. Laboratory Styles in Argentine Physiology. Isis, v. 85, n. 2, jun. 1994.

DORON, Claude Olivier. Races et Dégénérescence. L'emegence des savoir sur l'homme anormal. Tese (Doutorado em Filosofia). Université Paris Diderot, Paris, 2011.

DUARTE, Regina Horta. História dos animais no Brasil: tradições culturais, historiografia e transformação. HALAC, História Ambiental, Latinoamericana y Caribeña, v. 9, n. 2, 2009, pp. 16-44.

FERLA, Luís. Feios, sujos e malvados sob medida: a utopia médica do biodeterminismo, São Paulo (1920-1945). São Paulo: Alameda, 2009.

GOMES, Ana Carolina Vimieiro. Uma ciência moderna e imperial: a fisiologia brasileira no final do século XIX (1880-1889). Rio de Janeiro: Fiocruz; EDUEPB; Fino Traço, 2013.

HOCHMAN, Gilberto et al. The Path of Eugenics in Brazil: The dilemmas of miscegenation. In: LEVINE, Philippa; BASHFORD, Alison (editors). The Oxford Handbook of The History of Eugenics, Oxford University Press, Oxford, 2010,p.495.

HOCHMAN, Gilberto. O sal como solução? Políticas de saúde e endemias rurais no Brasil (1940-1960). Sociologias, Porto Alegre, ano 12, n. 24, mai.-ago. 2010b, pp. 158-193.

IBAÑEZ et al. De Instituto Soroterápico a Centro de Medicina Experimental: institucionalização do Butantan no período de 1920 a 1940. Cadernos de História da Ciência, v. 2, 2006, pp. 75-102.

KROPF, Simone Petraglia. Doença de Chagas, Doença do Brasil: ciência, saúde e nação, 1909-1962. Editora Fiocruz, 2006.

KROPF, Simone Petraglia. Carlos Chagas e os debates e controvérsias sobre a doença do Brasil (1909-1923). História, Ciências, Saúde - Manguinhos, v. 16, supl. 1, 2009, pp. 205-227.

KROPF, Simone Petraglia. Males do coração, ameaça ao trabalhador: o debate sobre a importância social das doenças cardíacas no Estado Novo. Anais do XXVII Simpósio Nacional de História. Natal, 2013.

LIMA, Rodrigo Ramos. "Terra de ninguém ou a terra de todo mundo?": a opoterapia como recomendação para o tratamento de homossexuais detidos no Laboratório de Antropologia Criminal do Rio de Janeiro (1931-1951). Dissertação (Mestrado em História das Ciências e da Saúde) - Casa de Oswaldo Cruz/Fiocruz, Rio de Janeiro, 2016.

LÖWY, Ilana. Imperfect pregnancies: a history of birth defects and prenatal diagnosis. Baltimore: Johns Hopkins University Press, 2017.

MANZONI, Juliana. A trajetória científica de Rudolf Kraus (1894-1932), entre Europa e América do Sul: elaboração, produção e circulação de produtos biológicos. Tese (Doutorado em História das Ciências e da Saúde), coc/Fiocruz, 2013.

MARQUES, Rita de Cássia; MITRE, Sérgio Munir Colina. Bócio endêmico em Minas Gerais: a pesquisa biomédica da terra dos "papudos". In: NASCIMENTO, Dilene Raimundo do; CARVALHO, Diana 
Maul de (Org.). Uma história brasileira das doenças. Brasília: Paralelo 15, 2004, pp.182-193.

OLIVEIRA JÚNIOR, Alcidésio de. De monstros a anormais: a construção da Endocrinologia Criminal no Brasil (1930-1950). Tese (Doutorado em História Cultural), Universidade Federal de Santa Catarina, 2012.

OUDSHOORN, Nelly. Beyond the natural body: an archeology of sex hormones. London: Routledge, 1995.

PITELLA, José Eymard Homem. O banco de dados do Prêmio Nobel como indicador da internacionalização da ciência brasileira entre 1901 e 1966. História, Ciências, Saúde - Manguinhos, Rio de Janeiro, v. 25, n. 2, abr.-jun. 2018, pp. 569-590.

PRESCOTT, Heather. "'I Was a Teenager Dwarf". The Social Construction of 'Normal' Adolescent Growth and Development in the United States". In: STERN, Alexandra Minna; MARKEL, Howard (Org.). Formative Years: Children Health in the United States, 1880-2000. Ann Arbor: The University of Michigan Press, 2000.

RAJ, Kapil. Beyond postcolonialism....and postpositivism - circulation and the global history of science. Isis,104 (02): 2013, pp. 337-347

SOUZA, Letícia Pumar Alves de. A ciência e seus fins: internacionalismo, universalismo e autonomia na trajetória do fisiologista Miguel Ozório de Almeida (1890-1953). Tese (Doutorado em História das Ciências e da Saúde). Casa de Oswaldo Cruz/Fiocruz, Rio de Janeiro, 2015.

TATTERSALL, Robert. Pancreatic Organotherapy for Diabetes,1889-1921. Medical History, 1995, 39: 288-316.

TEIXEIRA, Luis Antônio. Ciência e saúde na terra dos bandeirantes: a trajetória do Instituto Pasteur de São Paulo no período 1903-1916. Rio de Janeiro: Editora Fiocruz, 1995.

TEIXEIRA, Luis Antônio. A trajetória do Instituto Butantan: pesquisa e produção de imunobiológicos para a saúde pública. Revista Brasileira Inovação, Campinas (SP), 15 (1), p. 165-174, jan.jun. 2016.

VALLE, José Ribeiro do. José Ribeiro do Vale (depoimento, 1977). Rio de Janeiro, CPDOC, 2010. Disponivel em: <http://www.fgv.br/cpdoc/historal/arq/Entrevista496.pdf>. Acesso em: [04 fev. 2019].

VALLE, José Ribeiro do. Alguns aspectos da evolução da fisiologia no Brasil. In: FERRI, Mario Guimarães; MOTOYAMA, Shozo. História das Ciências no Brasil. São Paulo: EPU, 1979.

VALLE, José Ribeiro do. Thales Martins: pioneiro da endocrinologia experimental. Arquivos Brasileiros de Endocrinologia e Metabologia, v. 45, n. 5, supl. 2, nov. 2001, pp.786-790.

VASCONCELOS, F. de A. G. de. Fome, eugenia e constituição do campo da nutrição em Pernambuco: uma análise de Gilberto Freyre, Josué de Castro e Nelson Chaves. História, Ciências, Saúde - Manguinhos, v. VIII (2), jul.-ago. 2001, pp. 315-39.

Artigo recebido em: 29/10/2019

Artigo aceito em: 10/02/2020 